\title{
Normative Reasons as Reasons Why We Ought
}

\author{
Jacob M. Nebel
}

New York University

jakenebel@gmail.com

I defend the view that a reason for someone to do something is just a reason why she ought to do it. This simple view has been thought incompatible with the existence of reasons to do things that we may refrain from doing or even ought not to do. For it is widely assumed that there are reasons why we ought to do something only if we ought to do it. I present several counterexamples to this principle and reject some ways of understanding ought so that the principle is compatible with my examples. I conclude with a hypothesis for when and why the principle should be expected to fail.

This paper is about reasons. Many philosophers believe that there are at least three kinds of reasons, or senses of the count-noun reason. Consider the following examples:

(1) The reason why the town was abandoned was that zombies attacked.

(2) That the zombies attacked was a reason to abandon town.

(3) The reason for which they abandoned town was that zombies attacked.

The type of reason in (1) is usually called explanatory. The type in (2) is usually called normative. And the type in (3) is usually called motivating. My focus is on explanatory and normative reasons; I shall not discuss motivating reasons.

My view is that normative reasons are just explanatory reasons of a particular kind. More specifically, a reason for someone to do something is just a reason why she ought to do it.

The paper comes in four sections. In $\$ 1, \mathrm{I}$ introduce the view that normative reasons are a kind of explanatory reason. In \$2, I introduce the main problem with this view: it is thought to be incompatible with the existence of reasons to do things that we may refrain from doing 
or even ought not to do. Many people assume that there are reasons why we ought to do something only if we ought to do it. I present some counterexamples to this principle. In $\$_{3}$, I consider ways of understanding ought so that the principle is compatible with my examples. In $\$_{4}$, I present a hypothesis for when the principle should be expected to fail-namely, when ought is multidimensional, in a sense to be explained.

\section{Normative reasons}

Many philosophers take the concept of a normative reason-or of the counting-in-favour-of relation that holds between normative reasons and the acts or attitudes they support-as primitive. They are reasons primitivists. Many of these reasons primitivists hope to understand all normative concepts-for example, the concepts good, right, justified, and ought_-in terms of the concept of a normative reason (see Dancy 2004; Skorupski 2010; Parfit 2011; Scanlon 2014). Parfit, for example, believes that $S$ ought to $\phi$ means that $S$ 's reasons to $\phi$ are stronger than $S$ 's reasons to do otherwise (p. 33).

Opponents of reasons primitivism believe that the concept of a normative reason can be analysed in other terms (whether normative or non-normative). But it seems that no proposed analysis has been successful.

Kearns and Star (2008), for example, propose that a reason to $\phi$ is just evidence that one ought to $\phi$. Intuitively, however, many pieces of evidence that one ought to $\phi$ are not reasons to $\phi$. That some reliable book says I ought to exercise (with no explanation) is not, many people believe, a reason for me to exercise, although it may be good evidence that I ought to exercise (Broome 2013).

The reasons to exercise must, according to Broome, play a role in explaining why I ought to exercise (see also Toulmin 1950; Finlay 2001). ${ }^{1}$ Broome holds that all reasons are explanatory. There I agree with him. But what is their explanatory role?

Broome claims that, in one sense, a reason for someone to $\phi$ is a fact that explains why she ought to $\phi$. He calls these pro toto reasons. If there is a pro toto reason for $S$ to $\phi$, then $S$ ought to $\phi$. For if $p$ explains

\footnotetext{
${ }^{1}$ On other views, the reasons to exercise must play a certain role in explaining why it would be good to exercise (Raz 1999; Finlay 2014; Wedgwood 2015; Maguire 2016), or why there is reason (mass-noun) to exercise (Fogal 2016; Fogal and Sylvan 2017). I set aside these alternatives here.
} 
why $q$, then $q$ must be true. But not all normative reasons are pro toto reasons. There are normative reasons to do things that one may refrain from doing, and normative reasons to do things that one ought not to do. We have pro tanto reasons, which need not be decisive (in the sense of implying that we ought to do what they count in favour of doing). For example, that I am hungry may be a reason for me to steal a person's food, but I ought not to steal a person's food. That reason is not decisive.

On Broome's view, a pro tanto reason for $S$ to $\phi$ is explanatory, but it is not an explanation of why $S$ ought to $\phi$. He suggests that pro tanto reasons for $S$ to $\phi$ do not quite explain why $S$ ought to $\phi$, but rather play a certain role in a certain kind of explanation of why it is or is not the case that $S$ ought to $\phi$, whatever the case may be. The certain kind of explanation is a weighing explanation: one ought to $\phi$ because the

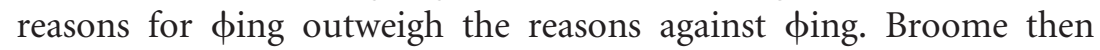
understands the counting-in-favour-of relation in terms of the forping role in an explanation of that kind. That is, when one ought to $\phi$, the facts that count in favour of $\phi i n g$ are just the facts that win out in the weighing explanation. ${ }^{2}$

Broome's account of pro tanto reasons strikes some philosophers as ad hoc or unilluminating. For one thing, our grip on which facts play which roles in explaining whether we ought to $\phi$ seems parasitic on our more basic understanding of which facts count in favour of $\phi$ ing (Schroeder 2007; Kearns and Star 2008; Brunero 2013). So Broome's account of pro tanto reasons in terms of weighing explanations seems not to provide a non-circular, informative account of what it is for some fact to count in favour of, or be a reason for, фing. Moreover, it is not obvious that normative reasons must participate in weighing explanations: reasons might not add up or interact in the way that weights add up and interact; weakening the metaphor of weighing to allow for such possibilities makes it less clear what weighing explanations are supposed to be (Hawthorne and Magidor forthcoming).

\footnotetext{
${ }^{2}$ Maguire (2018) emphasizes the features of normative reasons mentioned in the previous two paragraphs, namely, that reasons need not be decisive, and that they play a certain role in weighing explanations. He argues that these features (and another: gradable weights) are lacked by the kinds of considerations that support affective attitudes, and that we therefore have no reasons to have such attitudes. This conclusion may be in tension with my analysis of normative reasons. For we sometimes ought to have such attitudes, and presumably, when that is so, there are reasons why we ought to have such attitudes. So there can, on my analysis, be reasons for us to have those attitudes. I must therefore either reject Maguire's claim that reasons must have the features in question, or insist that the kinds of considerations that support affective attitudes have those features. I am currently inclined to prefer the first strategy.
} 
What I find most unattractive about Broome's view is that he posits two normative senses of the count-noun reason: pro toto and pro tanto senses. This move, it seems to me, multiplies senses beyond necessity and lacks a basis in either our ordinary or distinctively philosophical uses of the word. The main advantage of Broome's view is, I believe, its unification of normative and explanatory reasons. But this unification comes at the cost of an objectionably disjunctive account of normative reasons (Schroeder 2007; Kearns and Star 2008). This cost does not seem to me worth paying.

There is, however, a simpler account that captures the unifying advantage of Broome's view while avoiding its costs. On this account, a (normative) reason for $S$ to $\phi$ is just an (explanatory) reason why $S$ ought to $\phi$. That is the view I shall defend.

\section{Factivity}

The view that reasons to $\phi$ are reasons why we ought to $\phi$ seems to face the same problem that led Broome to distinguish pro tanto from pro toto reasons. The problem is that we can have reasons to do things that we may refrain from doing or even ought not to do. But if a reason to $\phi$ is a reason why one ought to $\phi$, then the existence of reasons to $\phi$ might seem to require that one ought to $\phi$. So my view might seem to rule out the possibility of non-decisive reasons.

The key assumption that generates this problem is:

Factivity: For any $p$, there is a reason why $p$ only if $p$ is true.

If Factivity is correct, and if reasons to $\phi$ are reasons why one ought to $\phi$, then there are reasons to $\phi$ only if one ought to $\phi$. That would rule out the existence of reasons to do things that we may refrain from doing or even ought not to do.

Factivity is assumed implicitly by Schroeder (2007, p. 35), Broome (2013, p. 50), and Skow (2016, p. 38), and explicitly by Lawler (1971, p. 167), Dancy (2000, p. 132), Grice (2001, p. 31), Finlay (2014, p. 109), and Hawthorne and Magidor (forthcoming). I know of only one philosopher who seems to reject it (see Wilson 1979, p. 273, although his non-factive usage may be merely stipulative).

I believe that Factivity is false. Just as we can have reasons to $\phi$ and reasons not to $\phi$, there can be reasons why we ought to $\phi$ and reasons why we ought not to $\phi$. But it cannot, I assume, be true both that we ought to $\phi$ and that we ought not to $\phi$. (In the next section, I consider ways in which this assumption might be rejected.) 
Consider the following example from Abraham Lincoln, regarding the proposed release of Confederate diplomats Jason Mason and John Slidell:

(4) Governor Seward, you will go on, of course, preparing your answer, which, as I understand, will state the reasons why they ought to be given up. Now I have a mind to try my hand at stating the reasons why they ought not to be given up. (Burlingame 2013, p. 227)

Lincoln thought that there were reasons why Mason and Slidell ought to be given up and reasons why they ought not to be given up. ${ }^{3}$ But surely he didn't think both that they ought to be given up and that they ought not to be given up.

Similar examples arise for other modals:

(5) $[\mathrm{T}]$ here exist good reasons why consent should be granted and good reasons why consent should be withheld [...]. (In re Cotton 1994, p. 185)

(6) Thus, subjects who were able to think of many reasons why an event would happen, and few reasons why it would not, judged that event to be likely. (MacLeod 1994, p. 119)

(7) There are many reasons why a free offer will work and reasons why it won't. (Carpenter 2015)

(8) This article presents four reasons why [Argentina] can [beat Uruguay], and four reasons why they can't. (Traquette 2011)

(9) [C]an a lightsaber cut through Superman? We [...] came up with reasons why it could and reasons why it couldn't. (Chen 2008)

These examples state that there are reasons why some $p$ should, would, can, could, or ought to be the case and also reasons why that $p$ should not, would not, cannot, could not, or ought not to be the case. But surely they do not presuppose both of these claims.

Examples like (4)-(9) are my main reasons for rejecting Factivity. But let me mention another reason to be suspicious of this principle. If reason why $p$ were factive with respect to $p$, then we might expect it to remain factive when negated. Karttunen (1971) observes that, except in

\footnotetext{
3 At least, he thought this at the time. The next day, Lincoln told Seward that he couldn't develop a satisfying argument for retaining Mason and Slidell.
} 
very special circumstances, negations of factive verbs presuppose the truth of their complements:

(10) John didn't [regret/forget/like] that he had not told the truth. (Karttunen 1971, p. 63)

This presupposes that John had not told the truth. ${ }^{4}$ But consider:

(11) That one is hungry is not a reason why one should steal another's food.

This does not presuppose that one should steal another's food. One could felicitously follow up (11) with something like 'One shouldn't steal another's food even if one is hungry'. By contrast, when the whyclause contains no modal verb, both is a reason why $p$ and is [no/not a] reason why $p$ seem factive with respect to $p$ :

(12) \#There's a reason why John didn't tell the truth. [And/but] John did tell the truth.

(13) \#That he was nervous isn't a reason why John didn't tell the truth. [And/but] John did tell the truth.

Those sound bad. When the why-clause contains no modal verb, reason why appears to work like more familiar factive constructions. We should therefore expect that if the construction remained factive when the why-clause contains a modal verb, then (11) would presuppose that one should steal another's food. But it doesn't.

The factivity of reason why might be thought to follow from the semantics of $w h y$-questions. It is natural to think that a reason why $p$ is an answer to the question 'Why p?' (Hieronymi 2011; Skow 2016). And many philosophers and linguists claim that questions of the form 'Why $p$ ?' presuppose that $p$ (Kim 1964; Bromberger 1966; Lawler 1971; Sober 1986; Temple 1988; Pietroski 2002; Fitzpatrick 2005; Brandtler 2008; Tomioka 2009). For example:

(14) Why didn't John tell the truth?

This question presupposes that John did not tell the truth. But, again, things seem different in the presence of modals:

(15) Why wouldn't John tell the truth?

\footnotetext{
${ }^{4}$ An anonymous referee points out that some utterances of (10) do not seem to carry this presupposition. Karttunen himself notes that one might utter a version of (10) with an emphasis on didn't to emphatically deny a previous assertion that carries the presupposition. But such cancelling contexts are very much the exception; in general, negative assertions involving factive verbs presuppose the truth of their complements.
} 
(16) Why shouldn't John tell the truth?

These questions do not presuppose that John wouldn't or shouldn't tell the truth (as Kim 1964, p. 363, acknowledges). So even if reasons why $p$ are answers to the question, 'Why $p$ ?', neither the answers nor the questions presuppose $p$ in certain cases.

The examples I have discussed so far use the plural reasons why and the indefinite singular a reason why. But the definite singular the reason why seems to work differently:

(17) That one is hungry is not the reason why one should steal another's food.

This sentence seems to presuppose that one should steal another's food. If the reason why $p$ is factive with respect to $p$, this may pose a problem for my view. For suppose that $r$ is a reason why $p$, and that there are no other reasons why $p$. Then $r$ is the reason why $p$. But it would be strange if the existence of a reason why $p$ and the existence of no other reasons why $p$ were enough to secure that $p$, when the existence of additional reasons why $p$ would be compatible with $p$ 's falsity. The apparent factivity of the reason why might therefore lead one to accept the factivity of reason why more generally.

However, the apparent factivity of the reason why seems to me a pragmatic feature of the definite singular, not a semantic feature of reason why more generally. For one thing, the presupposition can be cancelled by various modifiers:

(18) The only/best reason why one should steal another's food is that one is hungry. But that's not a good enough reason. One should never steal another's food!

This suggests that even though the reason why $p$ may normally convey that $p$, this is not because the existence of a unique reason why $p$ more generally presupposes that $p$. Moreover, the presupposition seems absent when the definite article modifies a plural noun:

(19) The reasons why one should steal another's food are silly.

This sentence seems not to presuppose that one should steal another's food. Indeed, one might assert (19) in an attempt to argue that one shouldn't steal another's food. I, therefore, doubt that the usual commitments of the reason why are due to the factivity of reason why more generally. 
Moreover, the definite singular seems to carry different commitments for talk of normative reasons as well:

(20) That one is hungry is not the reason to steal another's food.

Sentence (20) seems to presuppose that one ought to steal another's food. But the presupposition is cancelled or entirely absent in other cases:

(21) That one is hungry is not a reason to steal another's food.

(22) The only reason to steal another's food is that one is hungry.

(23) The reasons to steal another's food are silly.

(24) The best reason to steal another's food is that one is hungry. One can assert (21)-(24) in the course of denying that one should steal another's food. The same pattern seems to hold for both explanatory and normative reasons. This suggests that the apparent factivity of the reason why is not a problem for my analysis of normative reasons as explanatory reasons.

I have suggested that reason why $p$ is not always factive with respect to $p$. So there can be reasons why one ought to $\phi$ even if it's not the case that one ought to $\phi$. This means that my simple account of normative reasons is compatible with the existence of reasons to do things that we may refrain from doing or even ought not to do. There is no need to distinguish between pro tanto and pro toto reasons. All normative reasons are explanatory reasons of the same kind.

\section{Alternative oughts}

In \$2, I denied that reason why $p$ is factive with respect to $p$. My main reasons for denying factivity were examples (4)-(9), which say that there are reasons why some $p$ should, would, could, can, will, or ought to be the case, and reasons why $p$ should not, would not, could not, cannot, will not, or ought not to be the case. In this section, I consider alternative explanations of this data.

After presenting examples (4)-(9), I said that although there are reasons why we ought to $\phi$ and reasons why we ought not to $\phi$, surely it's not the case that we both ought and ought not to $\phi$. Abraham Lincoln, for example, was not presupposing both that Mason and Slidell ought to and ought not to be released. Some philosophers, though, might deny this.

This strategy could be pursued in at least two ways. One way would read the oughts in question as somehow attenuated in strength. The 
other way would differentiate between the modal parameters or flavours of the oughts in question, in a sense that I shall explain. But let me start with the strategy of attenuation. ${ }^{5}$

\subsection{Attenuation}

I have been assuming that the oughts in question are all things considered oughts. This may be the sense that reasons primitivists analyse in terms of normative reasons: we ought to $\phi$ (in this all-things-considered sense) if and only if we have most reason to $\phi$. We cannot have most reason to $\phi$ and most reason not to $\phi$. In this sense of ought, it cannot be the case both that we ought to $\phi$ and that we ought not to $\phi$.

Some philosophers countenance a pro tanto sense of ought. This sense could be understood in various ways. According to Crisp (2015, p. 153), you pro tanto ought to $\phi$ just in case, to some extent, you ought to $\phi$. According to Reisner (2013), you pro tanto ought to $\phi$ just in case, if there were no other relevant considerations, you ought to $\phi$. On these weaker readings, the existence of reasons why we ought to $\phi$ and reasons why we ought not to $\phi$ is compatible with Factivity, so long as these oughts are merely pro tanto.

I am not convinced that this is a bona fide sense of ought. If it were, then we might expect these readings to be eligible without explicitly qualifying the ought with phrases like to some extent or if there were no other relevant considerations. But these reading do not seem eligible without explicit qualification. For example, if someone would enjoy torturing puppies, she might have some reason to do so. And perhaps if all other things were equal-that is, if there were no other relevant considerations in favour or against torturing puppies-it would be true that she ought to torture puppies. But there seems to be no sense of ought in which she ought indeed to torture puppies. When a philosopher says that someone pro tanto ought to do something, this seems to me a technical way of saying that she has some reason to do something, or that it would be the case that she ought to do it if other

\footnotetext{
${ }^{5}$ One response that I do not consider here is that my examples involve genuine deontic dilemmas in which, all things considered, we both ought to and ought not to $\phi$. As an anonymous reviewer suggests, that is implausible because even if such dilemmas are possible (see, for example, van Fraassen 1973; Horty 2003; Horty 2012, ch. 4), we should expect them to be rare; the mere existence of reasons to and reasons not to should not generate tragic dilemmas (although see Sachs 2015). Moreover, in order to address all of (4)-(9), there would have to be not just deontic dilemmas (involving deontic oughts and shoulds), but also genuine dilemmas of other modal flavours involving conflicting wills, woulds, cans, and coulds. That sort of view has no precedent, as far as I am aware.
} 
things were equal. It does not clarify an independently existing sense of ought that speakers like Lincoln would use in statements like (4).

It might be thought that statements of Rossian (1930) duties like 'We ought to keep our promises' use ought in a pro tanto sense. After all, we cannot conclude from the fact that we ought to keep our promises and that $S$ promised to $\phi$ that $S$ ought to $\phi$ all things considered. But it is more plausible that ought has its ordinary sense throughout, and that what ought to be the case-that is, that we keep our promises-is a generic, rather than universal, generalization. Because it is generic, it does not entail that whenever someone promises to do something, she ought to do it. We do not need a pro tanto sense of ought to account for Rossian duties, because genericity is sufficient to distinguish them from absolute requirements.

Moreover, even if there is a pro tanto sense of ought, appealing to such a sense might be a merely partial solution, for two reasons. First, it is doubtful that there are pro tanto senses of could, can, will, and would. And without such senses, the view cannot account for examples (6)-(9). Second, there may be cases in which one says that there are reasons why some $p$ ought to be the case all things considered and reasons why that $p$ ought not to be the case all things considered. Consider Lincoln's (4). Plausibly, Seward was giving reasons why, all things considered, Mason and Slidell ought to be given up, and Lincoln was intending to give reasons why, all things considered, Mason and Slidell ought not to be given up. Appealing to an attenuated sense of ought does not save Factivity if one can assert the existence of reasons why, all things considered, we ought to $\phi$, and reasons why, all things considered, we ought not to $\phi$.

\subsection{Differentiation}

Appealing to attenuated oughts is one way of maintaining that the oughts in question are compatible. Another way is to distinguish between the modal parameters or flavours of the oughts in question, in a sense that I shall now explain.

The conventional wisdom in linguistics maintains that sentences containing ought, should, and other modals express different propositions depending on contextually relevant background conditions and standards. According to Kratzer (1977)'s influential version of this view, they quantify over possible worlds. The context supplies a way of restricting the set of possible worlds to a relevant domain, which 
forms the modal base. For example, suppose that a hurricane has just passed, and someone says:

(25) The bridge ought to have collapsed.

The modal base here might only include worlds in which, among other things, the hurricane occurs. But what has to be true of the worlds in the modal base for (25) to come out true?

On the orthodox view, ought is treated as a universal quantifier. But of course not all worlds in the modal base are worlds in which the bridge collapses: one might assert (25) after watching the bridge withstand the hurricane. Kratzer's proposal is that we somehow rank the worlds, and that (25) is true just in case the bridge collapses in all the top-ranked worlds. The mode of ranking worlds is the ordering source, which (for Kratzer) consists of a set of propositions. For deontic modals, the ordering source might be a set of laws or moral requirements. For epistemic modals, it might be a set of propositions that are normal, stereotypical, probable, or otherwise reasonable to expect. We rank worlds by their closeness to the ideal-that is, satisfaction of all propositions in the ordering source. For example, (25) is true just in case the bridge collapses in all the most normal worlds in the modal base.

Many aspects of Kratzer's semantics are controversial. But the core features of the account that are relevant for our purposes are shared by most of the alternatives that have been proposed. For example, one radical departure from Kratzer's semantics holds that modals do not quantify over possible worlds, but should instead be understood on the model of gradable adjectives (Lassiter 2011). This view starts from probabilities and degrees of obligation or desirability, and understands ought in terms of these scalar notions. Other views add additional ordering sources for ought, hold that ought requires the relevant proposition to hold only in most of the best worlds, allow the ordering source to vary with the agent's or speaker's evidence, replace propositions with event-descriptions or actions, or rank options (understood as sets of worlds) rather than worlds (see Von Fintel and Iatridou 2005; Chrisman 2012; Silk 2013; Cariani 2011). These departures from the orthodox view are, I think, harmless for our purposes. We can use Kratzer's semantics in the interest of simplicity, as long as what we ought to do is a function of some ranking of some contextually relevant items according to relevant standards.

Does this view help to maintain Factivity in light of statements like (4)-(9)? This depends on how plausible it is that, when one asserts the 
existence of reasons why one ought to $\phi$ and reasons why one ought not to $\phi$, the oughts in question do not share the same modal base and ordering source. If the modal base or ordering source differs between the oughts, then it may be true (given one modal base and ordering source) that we ought to $\phi$ and true (given another modal base or ordering source) that we ought not to $\phi$.

A shift in modal base may be plausible in some cases. Recall (6):

Thus, subjects who were able to think of many reasons why an event would happen, and few reasons why it would not, judged that event to be likely.

It may be tempting to think that each would holds fixed different circumstances (although I question this later). Given some circumstances, the event would happen. Given other circumstances, the event would not happen. So the woulds may both be true. Similar stories may apply to (7) and (8) — which use will and can, respectively-although I won't spell them out.

A shift in modal base is less plausible for certain cases involving deontic modals:

(26) So far you've given two reasons why Kelly should bring Evelyn's picture out of the rain and one reason why she should leave it there. The two reasons why Kelly should bring Evelyn's picture out of the rain are that Kelly shouldn't be selfish and that it's a shame to let a beautiful picture be ruined. The reason why Kelly should leave it there is that Evelyn needs to learn to be more responsible. (Waggoner et al. 1995, p. 585)

It is hard to see what the difference between the modal bases would be in (26). Perhaps one modal base includes that Kelly shouldn't be selfish and that it's a shame to let a beautiful picture be ruined, whereas the other includes that Evelyn needs to learn to be more responsible. But it seems possible that both shoulds hold fixed all these facts: there may be reasons why, even though Evelyn needs to learn to be more responsible, Kelly should bring Evelyn's picture out of the rain, and reasons why, even though Kelly shouldn't be selfish and it's a shame to let a beautiful picture be ruined, Kelly should leave Evelyn's picture out in the rain.

In (26), a shift in ordering source seems to me more plausible than a shift in modal base. That Kelly shouldn't be selfish and that it's a shame to ruin a beautiful picture may explain why, ordering alternatives in some way that gives pride of place to Kelly's character or the appreciation of beauty, it is best to bring the picture out of the rain. 
The need to teach Evelyn a lesson may explain why, ordering alternatives in some way that gives pride of place to Evelyn's character, it is best to leave the picture out in the rain. On this view, the shoulds are interpreted relative to the same set of possible worlds, but these worlds are ordered according to different standards.

It is not clear what features of the sentences are supposed to cause the shifts in modal base or ordering source. Most of the examples state that there are reasons why $p$ should, can, will, would, or ought to be the case and reasons why $p$ should, can, will, would, or ought not to be the case, without stating what those reasons are. What features of the sentences would make one modal base or ordering source salient for one use of the clause but not for the other?

In other cases where a shift in modal base or ordering source is plausible, there is a good account of what causes that shift. For example, consider the following argument:

(27) (P1) If you want to kill people for fun, you ought to kill them with a chainsaw. ${ }^{6}$

(P2) You want to kill people for fun.

(C) So, you ought to kill people with a chainsaw.

The premises may be true, but the conclusion seems false. We seem unable to detach the ought claim in the consequent of $\left(\mathrm{P}_{1}\right)$. One Kratzerian story about this kind of argument is that we interpret the oughts relative to different ordering sources (Silk 2014, p. 9). For example, in ( $\mathrm{P} 1)$ we might be ordering alternatives according to what would best achieve your goals; this teleological ordering source may be made salient by the want in the antecedent. In (C) we might be ordering alternatives according to what would best conform to morality or some other set of norms; a deontic ordering source may be made salient by mentioning such morally fraught things as guns. I do not claim that this story is correct. My claim is that the plausibility of this story depends on its account of what predicts the teleological interpretation of the ought in $\left(\mathrm{P}_{1}\right)$ and the deontic interpretation of the ought in (C). Without this account, the story would not provide a good explanation of the data.

Similarly, a proponent of the view under consideration - that when there are reasons why we ought to $\phi$ and reasons why we ought not to

\footnotetext{
${ }^{6}$ There is a sizable literature on these so-called 'anankistic conditionals'. See, for example, Sæbø (2001); Von Fintel and Iatridou (2005); Huitink (2005); von Stechow, Krasikova, and Penka (2006); Finlay (2014, ch. 3); Condoravdi and Lauer (2016); Finlay (2016).
} 
$\phi$, these oughts are interpreted relative to different modal bases or ordering sources-owes us an account of what predicts this difference. What makes one modal base or ordering source salient for one ought but another modal base or ordering source salient for the other? In (27), there are other expressions in the sentences that seem to make one interpretation more salient than another. But there seem to be no such expressions in the examples we are considering. Without an account of what causes the shift in ordering source or modal base in our examples, the story provides a weak explanation of the data. ${ }^{\text {? }}$

One might reply as follows:

Saying that there are reasons why we ought to $\phi$ makes salient some modal base and ordering source relative to which ping is best, because it presupposes that we ought to $\phi$; so we interpret the ought in such a way that it comes out true. Similarly, saying that there are reasons why we ought not to $\phi$ makes salient some other modal base or ordering source relative to which the speaker thinks not $\phi i n g$ is best, because it presupposes that we ought not to $\phi$.

But embedding oughts in factive environments does not generally lead us to interpret them relative to different modal parameters. Consider:

(29) \#Cat knows that we ought to $\phi$. Dana knows that we ought not to $\phi$.

That sounds bad, to my ear. But, according to the view under consideration, saying something that presupposes that we ought to $\phi$ makes salient some modal base and ordering source relative to which ping is best, and then saying something that presupposes that we ought not to $\phi$ makes salient some other modal base or ordering source relative to which not ping is best. So why don't we shift the modal base or ordering source accordingly for (29)? The first sentence presupposes that we ought to $\phi$, and the second presupposes that we

\footnotetext{
7 But consider the following abomination uttered by Anakin Skywalker after his mother dies in Attack of the Clones:

(28) But I couldn't... Why did she have to die? Why couldn't I save her? I know I could have.

One might claim that there must be a shift in the relevant modal base or ordering source, because Anakin presupposes both that he could and that he couldn't have saved his mother. And yet nothing would signal which particular modal base or ordering source is relevant to each sentence.

But I read (28) differently: it seems to me that Anakin changes his mind after the ellipses: he starts to say that he couldn't have saved her but then takes it back. This fact is obscured either by Hayden Christensen's acting or by George Lucas's writing.
} 
ought not to $\phi$. But it is unnatural to read these oughts differently in order to accept both presuppositions. The natural reading of (29) interprets these oughts the same way. So it remains unclear what would cause a shift in the modal base or ordering source in our examples.

I do not deny that modals like ought are context-sensitive in the way required by the strategy of differentiation. My claim is merely that the appeal to context-sensitivity does not save the factivity of reason why from the apparent counterexamples. Consider examples involving other context-sensitive expressions:

(30) Cat looked outside and saw that it was raining.

(31) Dana looked outside and saw that it wasn't raining.

Sentences (30) and (31) can both be true because it may have been raining where Cat was and not raining where Dana was. But that doesn't make it felicitous to assert:

(32) \#Cat saw that it was raining, and Dana saw that it wasn't raining.

We naturally consider the conjuncts according to a fixed contextual parameter-for example, a single time and place (see Moss 2015, p. 49). ${ }^{8}$ Similarly, there may be cases in which it is felicitous to assert that one ought to $\phi$ and felicitous to assert that one ought not to $\phi$, because we interpret these oughts relative to different contextual parameters, but this doesn't make it felicitous to assert that one ought to $\phi$ and that one ought not to $\phi$. And one would expect that if reason why $p$ were factive with respect to $p$, it would be infelicitous to assert that there are reasons why one ought to $\phi$ and reasons why one ought not to $\phi$; we would expect these oughts to be interpreted according to the same contextual parameters, much as in (32).

I said earlier that an appeal to different modal bases might seem plausible for some of my examples involving non-deontic modals. But, for the reasons given above, I do not think this strategy of differentiation can plausibly explain all the relevant data-for example, sentences (26), (4), and (5). One possible reaction to this failure would be to appeal to shifts in contextual parameters for some of the examples

\footnotetext{
${ }^{8}$ (32) may have an acceptable reading in certain contexts-for example, if the speaker wishes to draw attention, in a playful or paradoxical way, to the fact that Cat and Dana are in different locations with different climates. But this rhetorical flourish seems to exploit the fact that the point should, strictly speaking, be expressed with explicit reference to the different locations. Similar remarks apply to (29).
} 
but not for the non-deontic examples. This would leave my main claim - that there can be reasons why $S$ ought to $\phi$ even if it's not the case that $S$ ought to $\phi$-intact. But other things being equal, a uniform explanation of our data would be preferable. We do not need to appeal to shifts in contextual parameters in order to explain any of the data. We can simply deny that reason why is factive.

For example, my interpretation of (6)-'Thus, subjects who were able to think of many reasons why an event would happen, and few reasons why it would not, judged that event to be likely'-is that both woulds share the same modal base: perhaps everything the relevant subjects know, or some other salient body of information. Neither the subjects nor the speaker is committed to thinking both that the event would and that the event would not happen, given those fixed parameters, because there can be reasons why it would (or would not) happen even if it's not the case that it would (not) happen. My interpretation seems preferable to the strategy of differentiation, on which the woulds in (6) must be interpreted relative to different modal bases. For that strategy may distort the meaning of the sentence. According to the strategy of differentiation, (6) describes subjects who were able to think of many reasons why, given some hypothetical constraints, an event would occur, and few reasons why, given other hypothetical constraints, the event would not occur. But that does not seem quite right. These subjects may very well have been able to concoct many reasons why, given various possible constraints beyond their ken, the event would not occur. They just could not think of many reasons why, in light of the information available to them, it would not occur, while being able to think of many reasons why, in light of that same body of information, it would occur. (This interpretation is, at the very least, an eligible reading, which suggests that a shift in modal base is not necessary.) Positing a change in modal base without any strong indicator of such a shift may therefore amount to changing the subject.

I have considered two ways of maintaining Factivity in light of examples (4)-(9). Neither attenuation nor differentiation seems to me successful. There are surely other ways of pursuing this strategy. But, for reasons that will emerge in the next section, they are unlikely to succeed if they are too specific to modals.

\section{Multidimensionality}

I have argued that there can be reasons why we ought to $\phi$ even if it's not the case that we ought to $\phi$. In $\S_{3}$, I considered the view that if 
there are reasons why we ought to $\phi$ and reasons why we ought not to $\phi$, then indeed we ought to $\phi$ and we ought not to $\phi$, but these oughts are consistent, because they are somehow attenuated or differentiated. I denied that these oughts should be understood as pro tanto or as relative to different modal parameters.

Both views considered in $\S_{3}$ are specific to ought and other modals. So these views fail to apply in (at least, prima facie) non-modal cases like (33)-(36):

(33) There are doubtless more reasons why grad school is worthwhile (and, assuredly, some reasons why it isn't) [...]. (Sharon 2013)

(34) As a result, seven reasons why being the first author is important and six reasons why it is not were identified as shown in Table 2. (Krasnova et al. 2012)

(35) For example, before leading a discussion on prohibition, assign each student to write three reasons why prohibition is a good idea and three reasons why prohibition is a bad idea. (Salsbury 2011)

(36) Identify reasons why competition is useful and why it is not useful in terms of healthcare cost, quality, and access. (Rakich, Longest, and Darr 2010, p. 4)

These sentences do not presuppose that grad school is both worthwhile and not worthwhile, that being the first author is both important and not important, that prohibition is both a good idea and a bad idea, or that competition is both useful and not useful. The predicates worthwhile, important, good, and useful are not being used in merely pro tanto senses. Nor does it seem to me likely that each predicate carries two different semantic values within each sentence.

I suggest that we try to understand what is going on in (33)-(36) and then see if the explanation generalizes to the cases involving modals.

One feature that examples (33)-(36) have in common is that worthwhile, important, good, and useful are gradable adjectives. Something can be somewhat worthwhile, very important, extremely good, or more or less useful. But, for some gradable adjectives $F$, we cannot say that there are reasons why a thing is $F$ and reasons why it isn't $F$ :

(37) ?There are reasons why John is tall and reasons why John isn't tall. 
(38) ?There are reasons why the table is long and reasons why the table isn't long.

(39) ?There are reasons why the box is heavy and reasons why the box isn't heavy.

These sentences seem unacceptable. This is because, in normal contexts, (37) presupposes that John is tall and that John isn't tall, (38) presupposes that the table is long and that it isn't long, and (39) presupposes that the box is heavy and that it isn't heavy. ${ }^{9}$ Moreover, the adjectival nature of the predicates in $(33)-(36)$ is inessential. Consider the following examples:

(40) There are many reasons why auto racing is a sport, and many reasons why it isn't. (Sun 2010)

(41) $[\mathrm{R}]$ emember that Immanuel Kant offers theoretical reasons why instrumental music is fine art, and then reasons why it is not fine art. (Gracyk 2013, p. 61)

What (40) and (41) have in common with (33)-(36), which is not shared by (37)-(39), is that the predicates are multidimensional. There are multiple ways or respects in which a thing can be worthwhile, important, a sport, good, useful, or fine art. Something can be one of these things in some respects but not in others. Not so for tall, long, and heavy - at least, in normal contexts. (In some contexts, these predicates can perhaps enjoy a kind of multidimensionality: for example, if John has an extremely tall hairdo but is otherwise of average height, or if a rhombus-shaped table has short sides but a long diagonal, or if a massive box is floating in a low-gravity environment. (37)-(39) may be heard as acceptable in such contexts, precisely due to their multidimensionality.) I conjecture that when $F$ is a multidimensional predicate, there can be reasons why a thing is $F$ and reasons why it isn't $F$. This is not because the semantic value of $F$ changes or because $F$ expresses only some degree of $F$ ness, but rather because the existence of such reasons requires only that the thing is $F$ in some respects but not in others. By contrast, when $F$ is a one-dimensional predicate, there cannot be reasons why a thing is $F$ and reasons why

${ }^{9}$ I admit that we can understand what a speaker is trying to say in uttering (37), (38), or (39) - perhaps that there are reasons why some would count John as tall and why some wouldn't, or that there are reasons why the table would count as long in some contexts and reasons why it wouldn't count as long in others-but our ability to understand what a speaker is trying to say in uttering a sentence is not dispositive of whether the sentence is felicitous. 
it isn't $F$, because such reasons would presuppose that it both is and isn't $F$.

Returning to the examples involving modals, I propose that we generalize the diagnosis of multidimensionality. There can be reasons why $p$ should, can, would, could, or ought to be the case and reasons why $p$ shouldn't, can't, wouldn't, couldn't, or ought not to be the case when and because these modal operators rank worlds along multiple dimensions. Proximity to an ideal-whether deontic, teleological, bouletic, stereotypical, or whatever-may depend on various factors. There can be trade-offs between morally relevant considerations, goals, desires, and standards of normalcy. Worlds can be close to the contextually relevant ideal in some respects but not in others.

The hypothesis is that whenever there are reasons why $p$ should, can, would, could, or ought to be the case and reasons why $p$ shouldn't, can't, wouldn't, couldn't, or ought not to be the case, the contextually relevant ideal ranks the relevant worlds according to how $F$ they are, and the $p$-worlds are $F$ in some respects but not in others. This hypothesis strikes me as plausible in examples (4)-(9) of \$2. Many different kinds of factors may be relevant to whether the Confederates ought to be returned, consent should be granted, some arbitrary event would happen, a free offer will be effective, Argentina can beat Uruguay, and a lightsaber can cut through Superman.

I have not said what dimensions are or how they are structuredfor example, whether a dimension requires a precise cardinal scale of degrees. Nor have I tried to identify the dimensions associated with different kinds of modals, to explain how dimensions combine to form a multidimensional ideal, or to settle whether such ideals are to be understood in terms of Kratzerian ordering sources. I wish to remain neutral on such questions.

If my hypothesis in this section is correct, then it is clear how there can be reasons to $\phi$ and reasons not to $\phi$ on my account of normative reasons. There can be such reasons only when and because whether we ought to $\phi$ depends on many different dimensions of an ideal. Some of these dimensions may favour $\phi i n g$, while others oppose $\phi i n g$. I find it hard to see how there could be such reasons if there were no respect

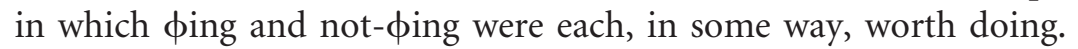

This story is distinct from the appeal to shifting ordering sources considered in \$3.2. I am not claiming that, whenever there are reasons why we ought to $\phi$ and reasons why we ought not to $\phi$, 'We ought to $\phi$ ' and 'We ought not to $\phi$ ' both express truths, with their respective oughts interpreted in different ways to isolate different dimensions. 
I am claiming instead that there can be such reasons even if neither 'We ought to $\phi$ ' nor 'We ought not to $\phi$ ' is true. There can be such reasons because reason why $p$ need not be factive with respect to $p$, when $p$ contains a multidimensional expression such as ought. This does not require the semantic value of ought to shift in the sentences at issue. (Nor, of course, does it rule out such a shift in other contexts.)

Let me conclude this section by briefly considering an objection. ${ }^{10}$ The view I have just sketched might seem too restrictive. For there might seem to be cases in which we have reasons to $\phi$ and reasons not to $\phi$, without there being multiple dimensions relevant to whether or not we ought to $\phi$. Suppose, for example, that we have only two

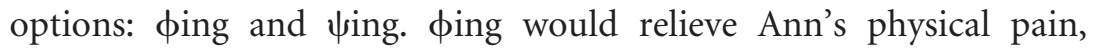
and 4ing would relieve Bob's physical pain; they would have no other effects. We have a reason to $\phi$-namely, that it would relieve Ann's physical pain —and a reason to $\psi$-namely, that it would relieve Bob's physical pain-but there might seem to be only one dimension relevant to whether we ought to $\phi$ or $\psi$ : namely, the relief of physical pain. If that is right, then there can be reasons to $\phi$ and reasons not to $\phi$ even if the relevant ideal is unidimensional.

But there are, I think, multiple dimensions relevant to the case just described: there are the effects on Ann, and there are the effects on Bob. If we treat each person's good as a different dimension of the relevant ideal, we can accommodate the case above. We have a reason to $\phi$ and a reason to $\psi$ because $\phi i n g$ is good in one way (namely, for Ann), and 4ing is good in another way (namely, for Bob).

This does not mean that the only dimensions ever relevant to what we ought to do are the effects on each person. The dimensions might be even more fine-grained so that, for example, they reflect different components of each person's well-being. So, for instance, we might have a reason to $\phi$ because $\phi i n g$ would be better for someone in some respect-for example, by decreasing the intensity or duration of some physical pain - even if ping would be worse for her (and everyone else) all things considered. And, depending on our normative theory, some dimensions might not be reducible to the good of any person at all (for example, inequality, on some egalitarian views). With a sufficiently fine-grained-and perhaps context-dependent (see Sassoon 2013) - partition of dimensions, we can answer the objection, so

\footnotetext{
${ }^{10}$ Thanks to an anonymous referee for pressing this objection.
} 
long as any source of reasons to $\phi$ can be identified with a dimension along which $\phi$ ing is worth doing. ${ }^{11}$

\section{Conclusion}

I have defended the view that a reason for someone to do something is a reason why she ought to do it. This view is attractive in its unification of normative and explanatory senses of the count-noun reason. But it has seemed incompatible with the existence of pro tanto reasons. The problem stems from the assumption that reason why $p$ is always factive with respect to $p$.

I have made three main claims in response to this problem. I claimed, first, that there can be reasons why we ought to $\phi$ and reasons why we ought not to $\phi$; second, that this is not best explained by attenuated or differentiated oughts; and third, that there can be such reasons when and because the relevant ideal is multidimensional.

If I am right that reason why is not factive, then why have so many philosophers thought otherwise? Here is a guess: they have assumed that a reason why $p$ must be a fact that (at least partially) explains why $p$, or plays some role in explaining why $p$-in short, that explanatory reasons are (at least partial) explanations. And explanation does seem factive: $q$ (even just partially) explains why $p$ only if $p$ is true. If explanation is indeed factive but explanatory reasons are not, then these philosophers have been wrong to assume that explanatory reasons just are explanations. ${ }^{12}$ For there can be reasons why $p$ even if $p$ is not the kind of thing — a fact—that can be explained. ${ }^{13}$

\footnotetext{
${ }^{11}$ The objector might worry that such a fine-grained conception of dimensions would make my view too permissive. But my appeal to multidimensionality was motivated by examples involving uncontroversially unidimensional adjectives, such as tall, long, and heavy. A finegrained partition of deontic ideals into many dimensions need not force us to recognize multiple respects in which things can be tall, long, or heavy.

${ }^{12}$ I am grateful to an anonymous referee for noticing how my arguments challenge this assumption. Interestingly, Wilson (1979, p. 273) introduces the reason why construction as a way of expressing a 'potential partial explainer', which-unlike an actual explanation-does not presuppose the truth of what it might potentially explain. So there is precedent for distinguishing reasons why from explanations.

${ }^{13}$ Thanks to Michael Deigan, Peter van Elswyk, Stephen Finlay, Ben Holguín, Jim Pryor, an anonymous referee, and the editors for helpful comments.
} 


\section{References}

Brandtler, Johan. 2008. 'Why We Should Ever Bother About WhQuestions: On NPI-Licensing Properties of Wh-Questions in Swedish'. Working Papers in Scandinavian Syntax 81: 83-121. http://lup.lub.lu.se/record/1296041.

Bromberger, Sylvain. 1966. 'Questions'. Journal of Philosophy 63 (20): 597-606.

Broome, John. 2013. Rationality Through Reasoning. Blackwell.

Brunero, John. 2013. 'Reasons as Explanations'. Philosophical Studies 165 (3): 805-24. doi:10.1007/s11098-012-9982-8.

Burlingame, Michael. 2013. Abraham Lincoln: A Life. JHU Press.

Cariani, Fabrizio. 2011. "Ought' and Resolution Semantics»'. Noûs. http://onlinelibrary.wiley.com/doi/10.1111/j.1468-0068.2011.00839.x/ full.

Carpenter, Cynthia. 2015. 'Getting Subscribers in 10 Easy Steps'. Make Money Chronicles. May 4. http://makemoneychronicles. com/1268/getting-subscribers-in-10-easy-steps/.

Chen, Jason. 2008. 'Can a Lightsaber Cut Through Superman?' Gizmodo. February 1. http://gizmodo.com/351747/can-a-lightsabercut-through-superman?utm_expid=66866090-67.e9PWeE2DSnKO bFD7vNEoqg.o\&utm_referrer=http://gizmodo.com/351747/can-alightsaber-cut-through-superman.

Chrisman, Matthew. 2012. 'On the Meaning of "Ought". Oxford Studies in Metaethics Vol. 7: 304.

Condoravdi, Cleo, and Sven Lauer 2016. 'Anankastic Conditionals Are Just Conditionals'. Semantics and Pragmatics 9 (0): 8-1-69. doi:10.3765/sp.9.8.

Crisp, Roger. 2015. 'Keeping Things Simple'. In Weighing and Reasoning, edited by Iwao Hirose and Andrew Reisner, 139-55. Oxford University Press. http://www.oxfordscholarship.com/ view/10.1093/acprof:oso/9780199684908.001.0001/acprof-

9780199684908-chapter-11.

Dancy, Jonathan. 2000. Practical Reality. Oxford University Press. 2004. Ethics Without Principles. Oxford; New York: Clarendon Press.

Finlay, Stephen. 2001. 'What Does Value Matter? The InterestRelational Theory of the Semantics and Metaphysics of Value'. Ph.D. Dissertation, University of Illinois at UrbanaChampaign. 
2014. Confusion of Tongues: A Theory of Normative Language. Oxford University Press. http://www.oxfordscholarship.com/ view/10.1093/acprof:oso/9780199347490.001.0001/acprof-978019934 7490.

2016. “'Ought”: Out of Order'. In Deontic Modality, edited by Nate Charlow and Matthew Chrisman. Oxford University Press. Fitzpatrick, Justin. 2005. 'The Whys and How Comes of Presupposition and NPI Licensing in Questions'. In Proceedings of the 24th West Coast Conference on Formal Linguistics. Somerville, MA: Cascadilla Proceedings Project, 138-45. Citeseer.

Fogal, Daniel. 2016. 'Reasons, Reason, and Context'. In Weighing Reasons, edited by Errol Lord and Barry Maguire. Oxford University Press.

Fogal, Daniel, and Kurt Sylvan 2017. 'Contextualism About Epistemic Reasons'. In The Routledge Handbook of Epistemic Contextualism, edited by Jonathan Jenkins Ichikawa. Routledge.

Gracyk, Theodore. 2013. 'Music, Indiscernible Counterparts, and Danto on Transfiguration'. Evental Aesthetics 2 (3): 58-86.

Grice, H. P. 2001. Aspects of Reason. Oxford; New York: Clarendon Press; Oxford University Press.

Hawthorne, John, and Ofra Magidor forthcoming. 'Reflections on the Ideology of Reasons'. In The Oxford Handbook on Reasons and Normativity, edited by Daniel Star.

Hieronymi, Pamela. 2011. 'Reasons for Action'. Proceedings of the Aristotelian Society 111 (3pt3): 407-27.

Horty, John F. 2003. 'Reasoning with Moral Conflicts'. Nô̂s 37 (4): 557-605. doi:10.1046/j.1468-0068.2003.00452.x.

-2012. Reasons as Defaults. Oxford, New York: Oxford University Press.

Huitink, Janneke. 2005. 'Analyzing Anankastic Conditionals and Sufficiency Modals'. Proceedings of ConSOLE XIII 135: 156.

In re Cotton. 1994, 526 N.W.2d 601. Michigan Court of Appeals. Karttunen, Lauri. 1971. 'Some Observations on Factivity'. Paper in Linguistics 4 (1): 55-69. doi:10.1080/08351817109370248.

Kearns, Stephen, and Daniel Star 2008. 'Reasons: Explanations or Evidence?*’. Ethics 119 (1): 31-56. http://www.jstor.org/stable/10. $1086 / 592587$.

Kim, Jaegwon. 1964. 'Inference, Explanation, and Prediction'. The Journal of Philosophy, 360-68.

Krasnova, Hanna, Tyge-F. Kummer, Kerstin Schäfer, and Natasha F. Veltri 2012. 'Let's Collaborate, but I Will Be the First 
Author! Exploring the Importance of the First Authorship for Is Researchers'. In ECIS, 144. http://boris.unibe.ch/47089/1/boris2. pdf.

Kratzer, Angelika. 1977. 'What 'Must' and 'Can' Must and Can Mean'. Linguistics and Philosophy 1 (3): 337-55. http://link. springer.com/article/10.1007/BFo0353453.

Lassiter, Daniel. 2011. 'Measurement and Modality: The Scalar Basis of Modal Semantics'. Ph.D. Dissertation, New York University. http://semarch.linguistics.fas.nyu.edu/Archive/WMzOWU2O/ Lassiter-diss-Measurement-Modality.pdf.

Lawler, John M. 1971. 'Any Questions?' In Papers from The Seventh Regional Meeting of the Chicago Linguistic Society, 163-73.

MacLeod, Andrew K. 1994. 'Worry and Explanation-Based Pessimism'. In Worrying: Perspectives on Theory, Assessment $d$ Treatment, edited by Graham Davey and Frank Tallis, 115-34. Wiley Series in Clinical Psychology. John Wiley \& Sons.

Maguire, Barry. 2016. 'The Value-Based Theory of Reasons'. Ergo, an Open Access Journal of Philosophy 3.

- 2018. 'There Are No Reasons for Affective Attitudes'. Mind, 127 (507), pp. 779-805.

Moss, Sarah. 2015. 'On the Semantics and Pragmatics of Epistemic Vocabulary'. Semantics and Pragmatics 8 (o): 5:1-81. doi:10.3765/ sp.8.5.

Parfit, Derek. 2011. On What Matters. V. 1. Oxford: Oxford University Press.

Pietroski, Paul M. 2002. Causing Actions. Oxford University Press. Rakich, Jonathon S., Beaufort B. Longest, and Kurt Darr ,eds. 2010.

Cases in Health Services Management. 5th ed. Baltimore: Health Professions Press.

Raz, Joseph. 1999. Engaging Reason: On the Theory of Value and Action. Oxford; New York: Oxford University Press.

Reisner, Andrew E. 2013. 'Prima Facie and Pro Tanto Oughts'. The International Encyclopedia of Ethics. http://onlinelibrary.wiley. com/doi/10.1002/9781444367072.wbiee406/full.

Ross, W. D. 1930. The Right and the Good. Edited by Philip StrattonLake. Oxford: Clarendon Press (reprinted 2002).

Sachs, Benjamin. 2015. 'Direct Moral Grounding and the Legal Model of Moral Normativity'. Ethical Theory and Moral Practice 18 (4): 703-16. doi:10.1007/s10677-015-9598-0.

Salsbury, Marina. 2011. 'Promoting Discussion and Participation in the Classroom | Ecology of Education'. December 22. 
http://ecologyofeducation.net/wsite/promoting-discussion-andparticipation-in-the-classroom/.

Sassoon, Galit. 2013. Vagueness, Gradability and Typicality: The Interpretation of Adjectives and Nouns. BRILL.

Scanlon, Thomas Michael. 2014. Being Realistic About Reasons. Oxford University Press.

Schroeder, Mark. 2007. Slaves of the Passions. Oxford; New York: Oxford University Press.

Sharon, William. 2013. '9 Reasons to Pursue a Master's Degree Besides the Paycheck'. The Huffington Post. October 16. http:// www.huffingtonpost.com/uloop/9-reasons-to-pursue-a-mastersdegree_b_4097366.html.

Silk, Alex. 2013. 'Evidence Sensitivity in Weak Necessity Deontic Modals'. Journal of Philosophical Logic, 1-33. http://link.springer. com/article/10.1007/s10992-013-9286-2.

- 2014. 'Why 'Ought' Detaches: Or, Why You Ought to Get with My Friends (If You Want to Be My Lover)'. Philosophers' Imprint 14 ( 7 ).

Skorupski, John. 2010. The Domain of Reasons. Oxford University Press. http://www.oxfordscholarship.com/view/10.1093/acprof:oso/ 9780199587636.001.0001/acprof-9780199587636.

Skow, Bradford. 2016. Reasons Why. Oxford, New York: Oxford University Press.

Sober, Elliott. 1986. 'Explanatory Presupposition'. Australasian Journal of Philosophy 64 (2): 143-49. doi:10.1080/0004840861234 2351.

Sun, N. 2010. 'Is Auto Racing A Real Sport?' Wikinut. November 2. http://guides.wikinut.com/Is-Auto-Racing-A-Real-Sport/1va33k2a/.

Sæbø, Kjell Johan. 2001. 'Necessary Conditions in a Natural Language'. In In Audiatur Vox Sapientiae: A Festchrift for Arnim von Stechow, Ed. Caroline Féry and Wolfgang Sternefeld, 427-49. Akademie Verlag.

Temple, Dennis. 1988. 'The Contrast Theory of Why-Questions'. Philosophy of Science, 141-51. http://www.jstor.org/stable/187825.

Tomioka, S. 2009. 'Why Questions, Presuppositions, and Intervention Effects'. Journal of East Asian Linguistics 18 (4): 253-71. doi:10.1007/s10831-009-9053-0.

Toulmin, Stephen Edelston. 1950. An Examination of the Place of Reason in Ethics. Cambridge University Press.

Traquette, Manuel. 2011. 'Copa America 2011: 4 Reasons Why Argentina Will and Will Not Beat Uruguay'. Bleacher Report. 
July 14. http://bleacherreport.com/articles/769029-copa-america2011-four-reasons-why-argentina-will-and-will-not-beat-uruguay. van Fraassen, Bas C. 1973. 'Values and the Heart's Command'. Journal of Philosophy 70 (1): 5-19.

Von Fintel, Kai, and Sabine Iatridou 2005. 'What to Do If You Want to Go to Harlem: Anankastic Conditionals and Related Matters'. Unpublished manuscript.

von Stechow, Arnim, Sveta Krasikova, and Doris Penka 2006. 'Anankastic Conditionals Again'. A Festschrift for Kjell Johan Sabø: In Partial Fulfilment of the Requirements for the Celebration of His 5oth Birthday, 151-71.

Waggoner, Martha, Clark Chinn, Hwajin Yi, and Richard C Anderson 1995. 'Collaborative Reasoning About Stories'. Language Arts, 582-89.

Wedgwood, Ralph. 2015. 'The Pitfalls of "Reasons"'. Philosophical Issues 25 (1): 123-43. doi:10.1111/phis.12054.

Wilson, Ian. 1979. 'Explanatory and Inferential Conditionals'. Philosophical Studies 35 (3): 269-78. doi:10.1007/BFo0357696. 